\title{
A Comparative Study of Intelligent Control System Tuning Methods for an Evaporator based on Genetic Algorithm
}

\author{
Hala A. Abdel-Halim \\ Hot Laboratory and Waste \\ Management Center, AEA, Cairo, \\ Egypt P.O 13759
}

\author{
Othman E. A. \\ Computers and Systems Eng. \\ Dept., Zagazig Univ., Zagazig, \\ Egypt
}

\author{
A. A. Sakr \\ Hot Laboratory and Waste \\ Management Center, AEA, Cairo, \\ Egypt P.O 13759
}

\author{
A. A. Zaki \\ Hot Laboratory and Waste Management Center, \\ AEA, Cairo, Egypt P.O 13759
}

\author{
A. A. Abouelsoud \\ Communications and Electronics Eng. \\ Dept., Cairo Univ., Cairo, Egypt
}

\begin{abstract}
This paper employs Genetic Algorithm to obtain the optimum parameters of an evaporator control system by using different tuning methods. Tuning methods consists of two main groups; first group consists of minimizing the performance indices factors separately such as; Integral of Absolute Error (IAE), Integral of Square Error (ISE), Integral of Time Absolute Error (ITAE) and Integral of Time multiplied with Square Error (ITSE).Second group consists of minimizing the performance indices factors separately plus the step response parameters such as; the rise Time (Tr), Settling Time (Ts), The Maximum Overshoot (Mp) and Steady state Error(Ess). Simulation Results prove that the second group of tuning methods give best performance, robust stability and improve the system robustness.
\end{abstract}

\section{General Terms}

Process Control, Intelligent Control, Optimal Control, Genetic Algorithm.

\section{Keywords}

Forced circulation evaporator, Genetic algorithm, Performance indices

\section{INTRODUCTION}

Controlling the process is the main problem in the industry. Achieving safety operation of the process and obtaining the product that has high degree of quality are the main challenges to control the process. Proportional, Integral and Derivative (PID) controller is most widely used controller industries because of its simplicity, robustness and successful practical application. In the classical tuning methods, optimal PID parameters are often hard to determine [1]. For this reason, many intelligent optimization techniques have been employed to determine the optimal parameters of PI/PID controller and hence improve the controller performances. Such intelligent optimization techniques include, Differential Evolution (DE) algorithm [2],[3], fuzzy systems [4-6], Ant Colony Optimization[7-8], , Particle Swarm Optimization (PSO)[9-10], Genetic Algorithm (GA) [1114].Great attention is to find tuning methods that lead to the optimal operation of the PID controllers. A control system is considered an optimum control system when its parameters are adjusted so that its performance index reaches an extreme value. A performance index is a quantitative measure of the performance of a system for the important system specifications, such as; Integral of Absolute Error (IAE), Integral of Square Error (ISE), Integral of Time Absolute Error (ITAE) and Integral of Time multiplied with Square Error (ITSE) [15]. In order to obtain the optimal control, a lot of research using intelligent techniques interest on taken some or all of these performance indices as cost functions [16-18]. And other such as in [19-23] take ITAE only as cost function because it has advantages of producing smaller overshoots and oscillations than the IAE (integral of the absolute error) or the ISE (integral square error) performance indices. In addition, it is the most sensitive of the three, i.e. it has the best selectivity. The ITSE (integral time-square error) index is somewhat less sensitive [24]. But ITAE cannot ensure to have a desirable stability margin [25].

In this paper, a comparison study is done by investigating the performance, stability and the system robustness of using tuning methods that consists of two groups; the first group includes the performance indices factors separately and the second group consists of performance indices factors separately plus the step response parameters in order to obtain the best cost function that give the optimal control system for the forced circulation evaporator example that by using genetic algorithm (GA) strategy.

The forced circulation evaporator is used to separate mixtures unable to be evaporating by conventional evaporating unit. Its applications in chemical industry, waste treatment plant, food products and pharmaceuticals. The evaporator requires for the safety operation and the quality of the processed product; the effective control for three parameters; the level of the solution in the separator part of the selected evaporator, the operating pressure and the percent of the concentration of the nonvolatile in the solution.

This paper contains 7 sections beside the introduction. In Section 2 is devoted for describing in details the used evaporation system. Section 3 we describe genetic algorithms. The proposed different objective functions are presented in

section 4. Applying GA to obtain the parameters of level control and to choose the parameters of the decoupler 
controller for evaporator system for the proposed different cost functions are illustrated in sections 5 and 6 . A comparison between the results obtained by GA is described in section 8. Section 9 gives the conclusion of paper.

\section{EVAPORATION SYSTEM}

The genetic algorithms are applied to the evaporation system [26].This system is a forced circulation evaporator, as shown in Figure 1, consisting of three main components; Evaporator, Separator and Condenser. Evaporator and Separator act as heat exchangers. The concentration of the feed solution which is mixed with the circulated solvent is increased by evaporating the mixtures from the feed steam. The separation of the vapor and the liquid is occurred in Separator. The vapor from Separator is condensed by flowing cooling water through Condenser. A nonlinear model was implemented using SIMULINK/MATLAB [27] as shown in Figure 1a in the appendix A. Then MATLAB is used to linearization the nonlinear model. A linear model is obtained from linearization the Simulink model at the nominal operating point as shown in Table 1a and Table 2a in the appendix A.

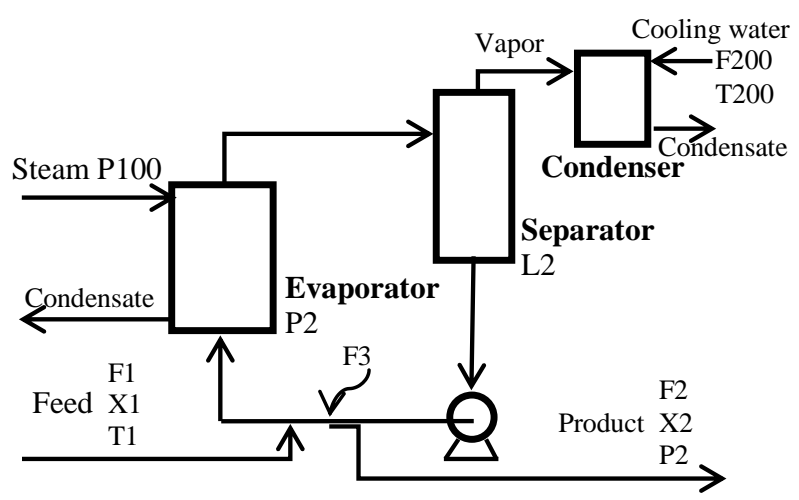

Fig 1: An Evaporator Layout

The corresponding linear state space representation is as follows:

$$
\left[\begin{array}{c}
\dot{L} 2 \\
\dot{X} 2 \\
\dot{P} 2
\end{array}\right]=A\left[\begin{array}{l}
L 2 \\
X 2 \\
P 2
\end{array}\right]+B_{i}\left[\begin{array}{c}
F 2 \\
P 100 \\
F 200
\end{array}\right]+B_{d}\left[\begin{array}{c}
F 3 \\
F 1 \\
X 1 \\
T 1 \\
T 200
\end{array}\right]
$$

Where:

$$
\begin{aligned}
A & =\left[\begin{array}{ccc}
0 & 0.0042 & 0.0075 \\
0 & -0.100 & 0 \\
0 & -0.0209 & -0.0558
\end{array}\right] \\
B_{i} & =\left[\begin{array}{ccc}
-0.0500 & -0.0019 & 0 \\
-0.0125 & 0 & 0 \\
0 & 0.0096 & -0.0018
\end{array}\right] \\
B_{d} & \\
= & {\left[\begin{array}{ccccc}
-0.0089 & 0.0444 & 0 & -0.0009 & 0 \\
0 & 0.0025 & 0.5000 & 0 & 0 \\
0.0447 & 0.028 & 0 & 0.0045 & 0.036
\end{array}\right] }
\end{aligned}
$$

The main controlled variable is the "Product Composition" (X2). For the safe operation and a voiding damaging of the installed equipment; operating pressure (P2) and level of liquid in the separator (L2) are also controlled variables. The manipulated variables are; product flow rate (F2), steam pressure (P100) and cooling water flow rate (F200). Other variables that affect the evaporator's performance, act as disturbances, namely F3 (circulating flow rate), F1 (feed flow rate), X1 (feed composition), T1 (feed temperature) and T200 (cooling water flow rate).

\section{GENETIC ALGORITHMS}

Genetic algorithms (GAs) belong to the larger class of evolutionary algorithms, which generate solutions to optimization problems using techniques inspired by natural evolution, such as inheritance, mutation, selection, and crossover [28].The genetic algorithm repeatedly modifies a population of individual solutions. At each step, the genetic algorithm selects individuals from the current population to be parents and uses them to produce the children for the next generation. Over successive generations, the population "evolves" toward an optimal solution.

The genetic algorithm can be used to solve a variety of optimization problems that are not well suited for standard optimization algorithms, including problems in which the objective function is discontinuous, non-differentiable, stochastic, or highly nonlinear.

Three main rules used in GA:

1. Selection Rules; select the individuals, called parents that contribute to the population at the next generation.

2. Crossover Rules; combine two parents to form children for the next generation.

3. Mutation Rules; apply random changes to individual parents to form children

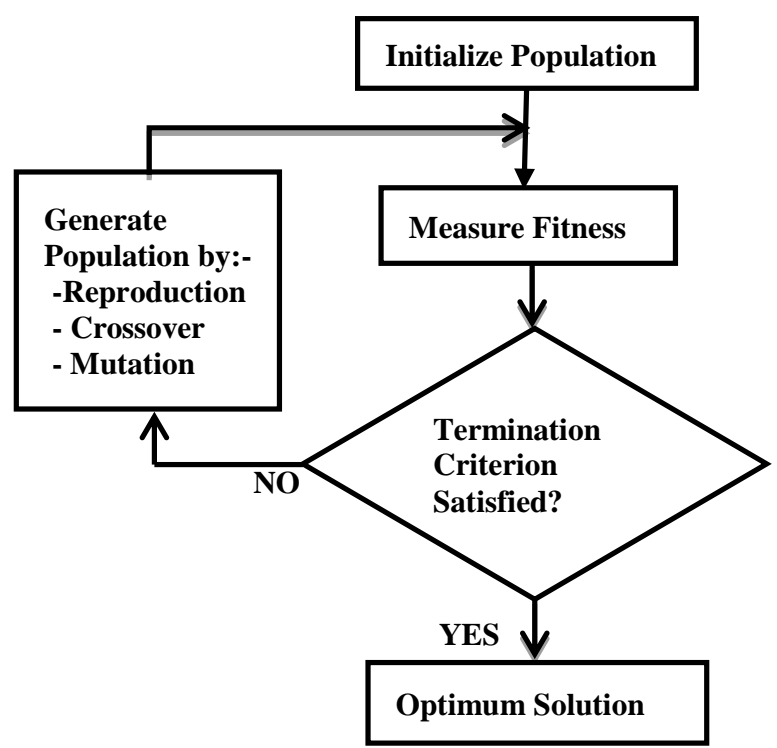

Fig 2: Flow diagram of Genetic Algorithm 


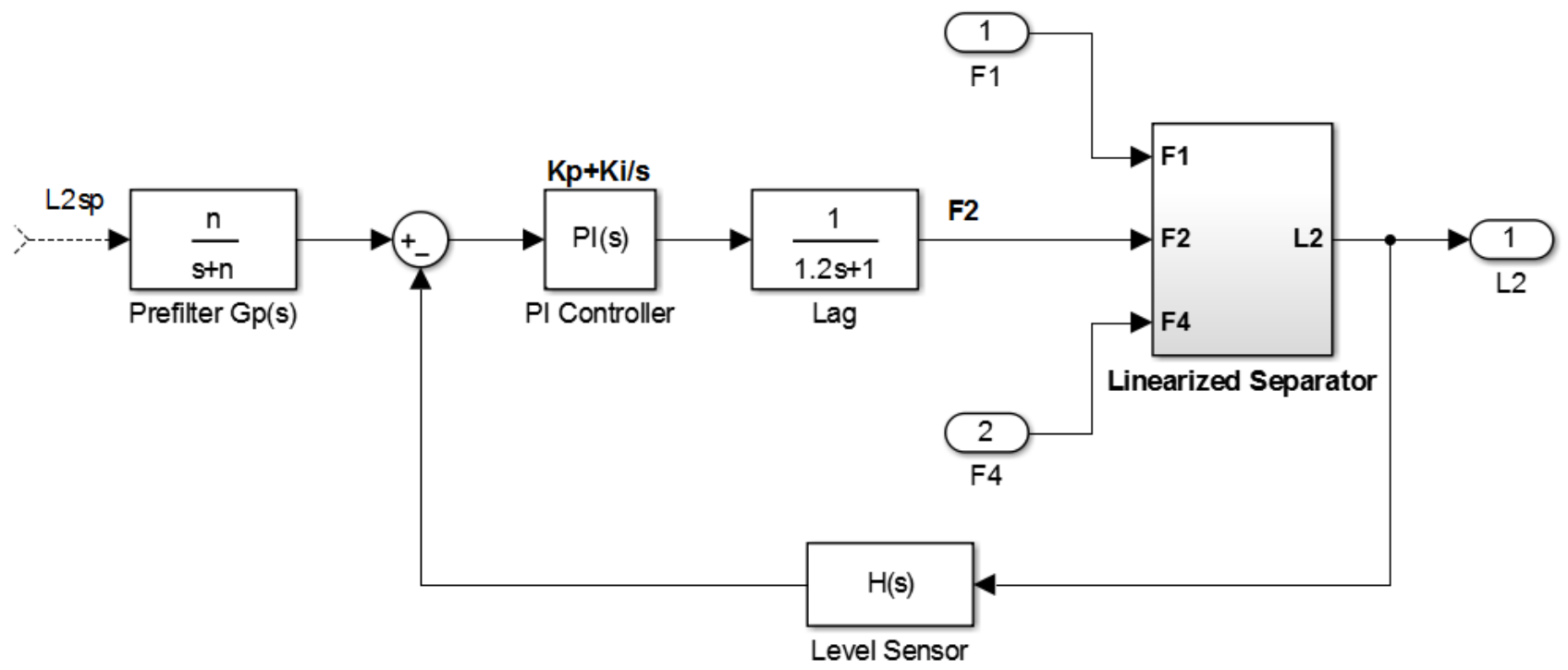

Fig 3: Feedback Level Control for the Linearized Separator System

As illustrated in Figure 2, a general scheme of a GA can be described as follows:-

1. Initialization of the population of chromosomes (set of randomly generated chromosomes).

2. Evaluation of the cost function (fitness) for all chromosomes.

3. Selection of parent chromosomes (reproduction).

4. Proceed with crossover and mutation operation and make up the new cluster.

5. Repeat Step 2, till the termination criterion is satisfied.

Here MATLAB global optimization for genetic algorithm toolbox [27] is applied on our case to obtain the optimized parameters for the evaporator control system. Some works recommend 20 to 100 chromosomes in one population [29]. The more the chromosomes number, the better the chance to get the optimal results. But in our case because of using limitations to control parameters, trial and error and also considering the execution time, it is found that choosing 10 chromosomes in each generation. Performing the genetic algorithm optimization by calling Function (ga) that requires essentially:-

Fitness function - the objective function is required to be minimized. Entering the fitness function in the form @ fitnessfun, where fitnessfun.m is a file that computes the fitness function.

Number of variables - the length of the input vector to the fitness function

\section{OBJECTIVE FUNCTIONS}

To find the parameters of each controller to control L2, X2 and P2 under an optimization problem, consider the following performance index parameters;

- Integral Absolute Error $(\mathrm{IAE})=\int_{0}^{\mathrm{t}}|\mathrm{e}(\mathrm{t})| \mathrm{dt}$

- Integral Square Error(ISE) $=\int_{0}^{t} \mathrm{e}^{2} \mathrm{dt}$

- Integral Time Absolute Error (ITAE) $=\int_{0}^{t} t|e(t)| d t$

- Integral Time Square Error (ITSE) $=\int_{0}^{t} t e^{2} d t$. Where $\mathrm{t}$ is the time interval and $\mathrm{e}(\mathrm{t})$ is the difference between set point and controlled variable. Addition taken the following parameters of a time response:

- Overshoot index (Mp)
- $\quad$ Settling Time index (Ts); for a time response of a system which index is the minimum time that there response reaches to absolute error of 0.05 .

- $\quad$ Rise Time( Tr)

- $\quad$ Steady state Error (Ess).

The suggested cost functions (objective functions) are consists of two groups:-

- First group is defined as: - IAE, ISE, ITAE, and ITSE.

- Second group is defined as:-

*IAE+ Step Response Parameters (SRP)

* ISE+SRP

$*$ ITAE+SRP

* ITSE+SRP

Where

$S P R=\omega_{0} \cdot T_{r}+\omega_{1} \cdot T_{S}+\omega_{2} \cdot M_{P}+\omega_{2} \cdot E_{S S}$

And the parameters $\omega_{0}, \omega_{1}, \omega_{2}$ and $\omega_{3}$ should be selected by the designer according to the case. In our case, take these parameters equal to 1 .

\section{IMPLEMENTATION OF THE LEVEL CONTROL SYSTEM}

The Level control system is implemented as shown in Figure 3. PI level control have 3 parameters; the proportion gain $(\mathrm{Kp})$, integration gain $(\mathrm{Ki})$ and an additional parameter $(\mathrm{n})$ of the prefilter Gp as shown in Figure 3 (which has the gain (n) and pole (n), is necessary to cancel the effect of zero of the PI controller, which will significantly affect the response of the control system [30].

The optimal tuning of different PI level controllers is done according to the different objective functions using GA. The proposed PI level controller manipulates the Product Flow rate F2 to adjust separator level L2. Table 1 indicates upper and lower bounds of PI level controllers.

Table 1. Upper and Lower Bounds of PI level Controller

\begin{tabular}{|c|c|c|c|}
\hline & $\mathbf{K}_{\mathbf{p}}$ & $\mathbf{K}_{\mathbf{i}}$ & $\mathbf{n}$ \\
\hline U.B & 30 & 30 & 1 \\
\hline L.B & 0 & 0 & 0 \\
\hline
\end{tabular}




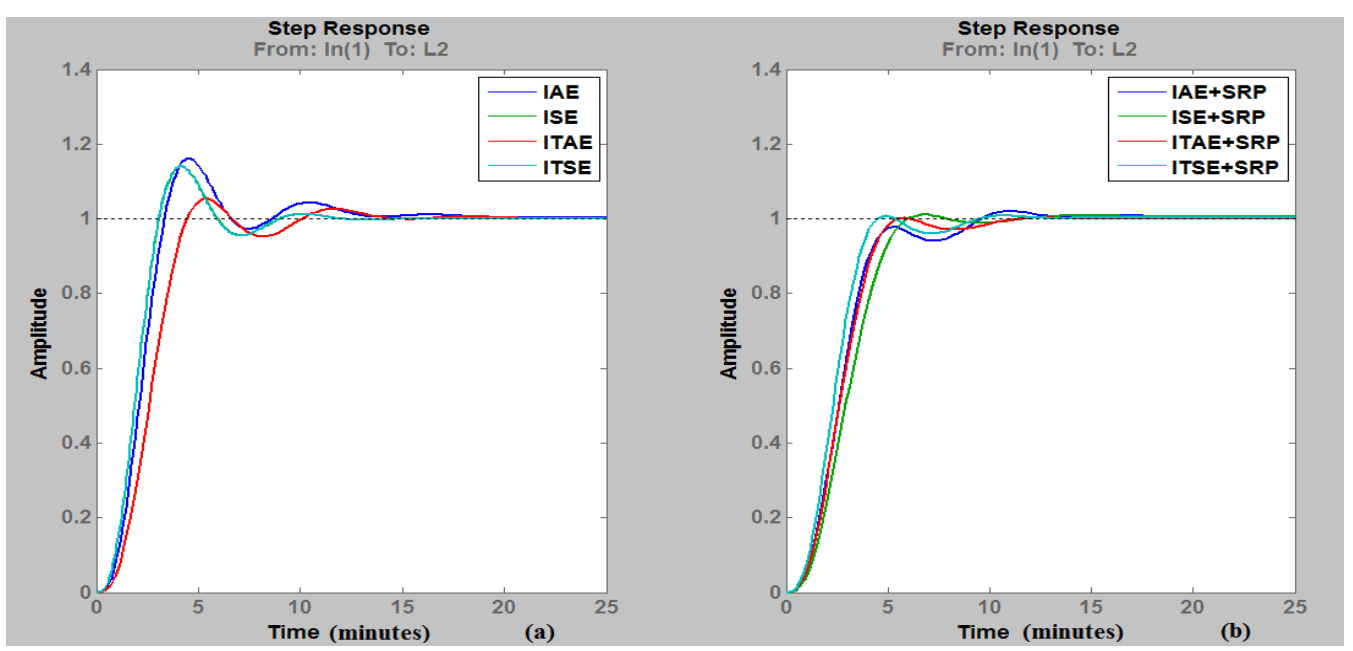

Fig 4: Step response of proposed Level controllers with two groups of different cost functions

Figures (4a) and (4b) show step responses for the proposed level controllers by GA using first group of cost functions (IAE, ISE, ITAE, ITSE) and second group of cost functions (IAE+SRP, ISE+SRP, ITAE+SRP, ITSE+SRP), respectively. In order to investigate more clearly the performance and stability of the different proposed level controllers, tables (3 and 4) indicate parameters of Level controllers using the two groups of cost functions, cost functions values, step response parameters and their gain margin (GM) and phase margin (PM), respectively.

Table 3 Parameters of Level controllers using cost functions; IAE, ISE, ITAE, and ITSE, their cost functions values, step response parameters and their gain margin (GM) and phase margin (PM) (the dashed row indicates its best in SRP or Stability)

\begin{tabular}{|c|c|c|c|c|c|c|c|c|c|c|c|}
\hline $\begin{array}{c}\text { Cost } \\
\text { Function }\end{array}$ & C.F.V ${ }^{*}$ & Kp & $\mathbf{K i}$ & $\mathbf{N}$ & $\begin{array}{c}\text { Tr } \\
\text { (min) }\end{array}$ & $\begin{array}{c}\text { Ts } \\
\text { (min) }\end{array}$ & $\begin{array}{l}\text { Mp } \\
(\%)\end{array}$ & Ess & SRP & $\begin{array}{l}\text { GM } \\
\text { (dB) }\end{array}$ & $\begin{array}{c}\text { PM } \\
\text { (deg) }\end{array}$ \\
\hline IAE & 2.63 & 30.000 & 4.8219 & 0.6365 & 1.99 & 12.18 & 16.16 & 0 & 30.33 & Inf & 48.19 \\
\hline ISE & 1.39 & 29.2856 & 0.0001 & 1.0000 & 1.87 & 8.329 & 14.06 & 0 & 24.26 & Inf & 64.36 \\
\hline ITAE & 6.29 & 25.9951 & 5.9177 & 0.3998 & 2.61 & 12.69 & 5.34 & 0 & 20.64 & Inf & 45.15 \\
\hline ITSE & 1.37 & 30.0000 & $\overline{0.0004}$ & 1.0000 & 1.84 & 8.24 & $\overline{14.16}$ & 0 & 24.24 & Inf & 63.50 \\
\hline
\end{tabular}

\section{C.V.F: abbreviation of Cost Function Value}

Table 4 Parameters of Level controllers using cost functions; IAE+SRP, ISE+SRP, ITAE+SRP, and ITSE +SRP, their cost functions values, step response parameters and their gain margin (GM) and phase margin (PM)

\begin{tabular}{|c|c|c|c|c|c|c|c|c|c|c|c|c|}
\hline $\begin{array}{c}\text { Cost } \\
\text { Function }\end{array}$ & P.I.V* & C.F.V* & Kp & $\mathbf{K i}$ & $\mathbf{N}$ & $\begin{array}{c}\operatorname{Tr} \\
\text { (min) }\end{array}$ & $\begin{array}{c}\text { Ts } \\
(\mathbf{m i n})\end{array}$ & $\begin{array}{l}\text { Mp } \\
(\%)\end{array}$ & Ess & SRP & $\begin{array}{l}\text { GM } \\
\text { (dB) }\end{array}$ & $\begin{array}{c}\text { PM } \\
\text { (deg) }\end{array}$ \\
\hline IAE+SRP & 2.9548 & 16.75 & 29.6782 & 5.3991 & 0.3724 & 2.84 & 8.96 & 2.0 & $1.11 \mathrm{e}-16$ & 13.80 & Inf & 46.54 \\
\hline ISE+SRP & 2.3034 & 12.30 & 18.3726 & 0.1333 & 0.5024 & 3.35 & 5.54 & 1.10 & $-2.22 \mathrm{e}-16$ & 10.0 & Inf & 83.22 \\
\hline ITAE+SRP & 5.0035 & 7.64 & 23.1784 & 0.0037 & 0.5279 & 2.95 & 9.46 & 0.22 & 1.11e-16 & 12.63 & Inf & 73.53 \\
\hline ITSE+SRP & 1.8987 & 13.65 & 29.9937 & 0.1781 & 0.5626 & 2.51 & 8.44 & 0.81 & 1.11e-16 & 11.75 & Inf & 62.91 \\
\hline
\end{tabular}




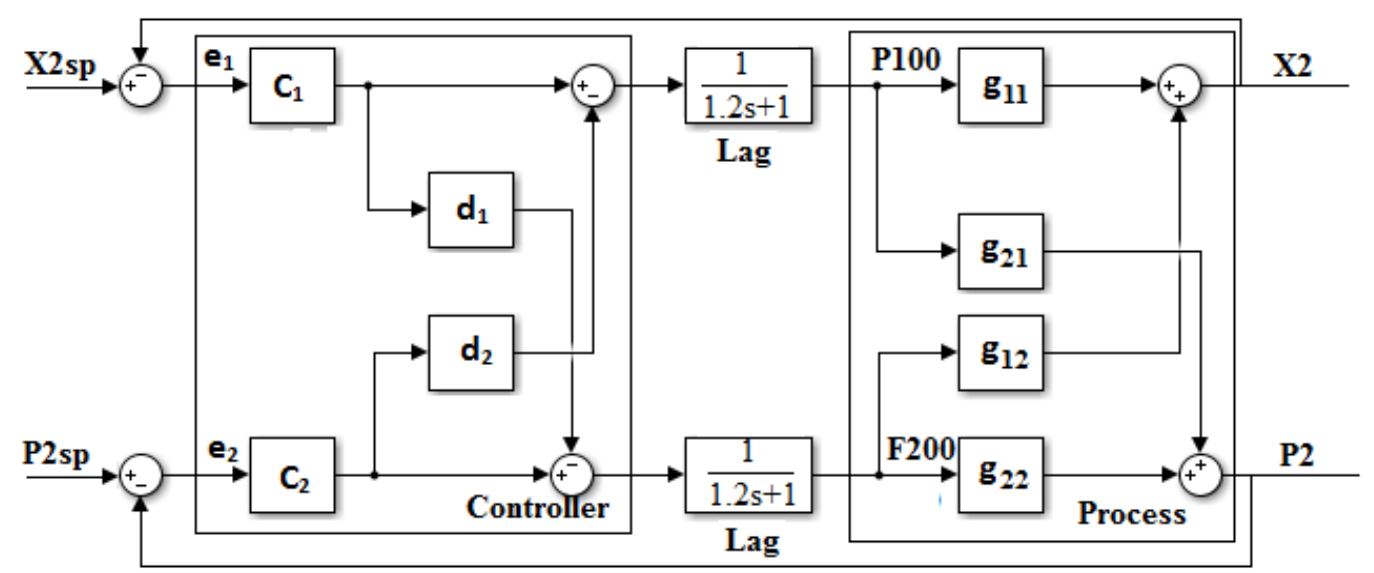

Figure 5 Multivariable (TITO) process with decoupling controller (controllers $\left[c_{1}\right.$ and $\left.c_{2}\right]$ and decouplers [ $d_{1}$ and $\left.d_{2}\right]$ )

\section{IMPLEMENTATION OF A DECOUPLER CONTROLLER}

The linearized model of the evaporator can be considered as Two-Input-Two-Output (TITO) multivariable system after the liquid level control loop L2-F2 was closed using the controllers as shown in the previous section.

As shown in Figure 5, the decoupler controller consists of two SISO controllers $\left(C_{1}\right.$ and $\left.C_{2}\right)$ and decouplers $\left(d_{1}\right.$ and $\left.d_{2}\right)$.As the control input F2, two lags are used for control inputs P100 and F200 as shown in Fig. 5. The first control goal for designing a decoupling controller is to cancel the interaction between control loops (P100-X2) and (F200-P2) by means of decouplers $d_{1}$ and $d_{2}$. These decouplers can be obtained by using the following equations [31]:

$$
d_{1}(\mathrm{~s})=\frac{g_{21}(s)}{g_{22}(s)}
$$

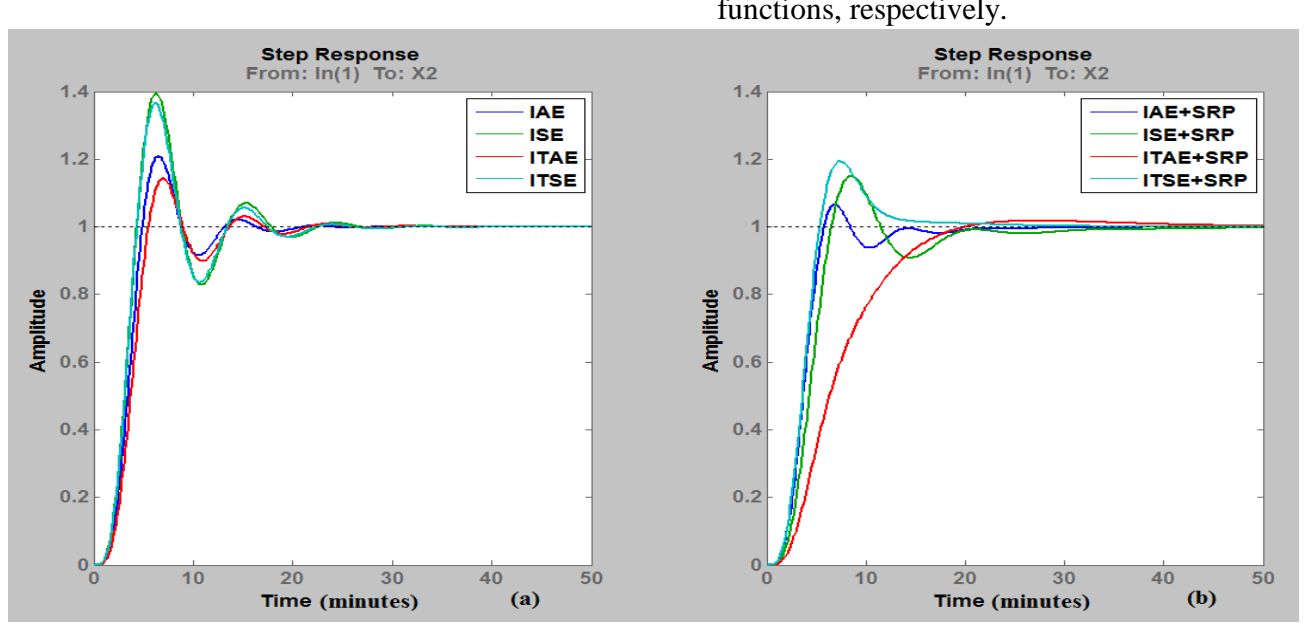

Fig. 6: Step response of proposed controllers $C_{1}$ with two groups of cost functions lead compensator. k) of a lead compensator $C_{2}$. functions, respectively.

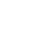

The second control goal is to tune the controllers $\mathrm{C}_{1}$ and $\mathrm{C}_{2}$ for the control loops (P100-X2) and (F200-P2) respectively, in order to achieve tradeoff between stability and performance. The controller $\mathrm{C}_{1}$ is a PI controller and before tuning controller $\mathrm{C}_{2}$, an important hint must be considered that the main aim for controlling P2 is to achieve the stability in operating the evaporator. So the proposed controller $\mathrm{C}_{2}$ is a

GA is used to obtain the values of two parameters (Kp and $\mathrm{Ki}$ ) of controller $\mathrm{C}_{1}$ and three parameters zero-pole gain $(\mathrm{z}, \mathrm{p}$ and

Figures (6 and 7) show the step response of the proposed controllers $\mathrm{C}_{1}$ and $\mathrm{C}_{2}$ using the two groups of cost functions, respectively. Tables $(6$ and7) indicate the optimized parameters of the controllers' $\mathrm{C}_{1}$ and $\mathrm{C}_{2}$, their step response parameters and their stability parameters that obtained by using GA technique depending on the two groups of cost 


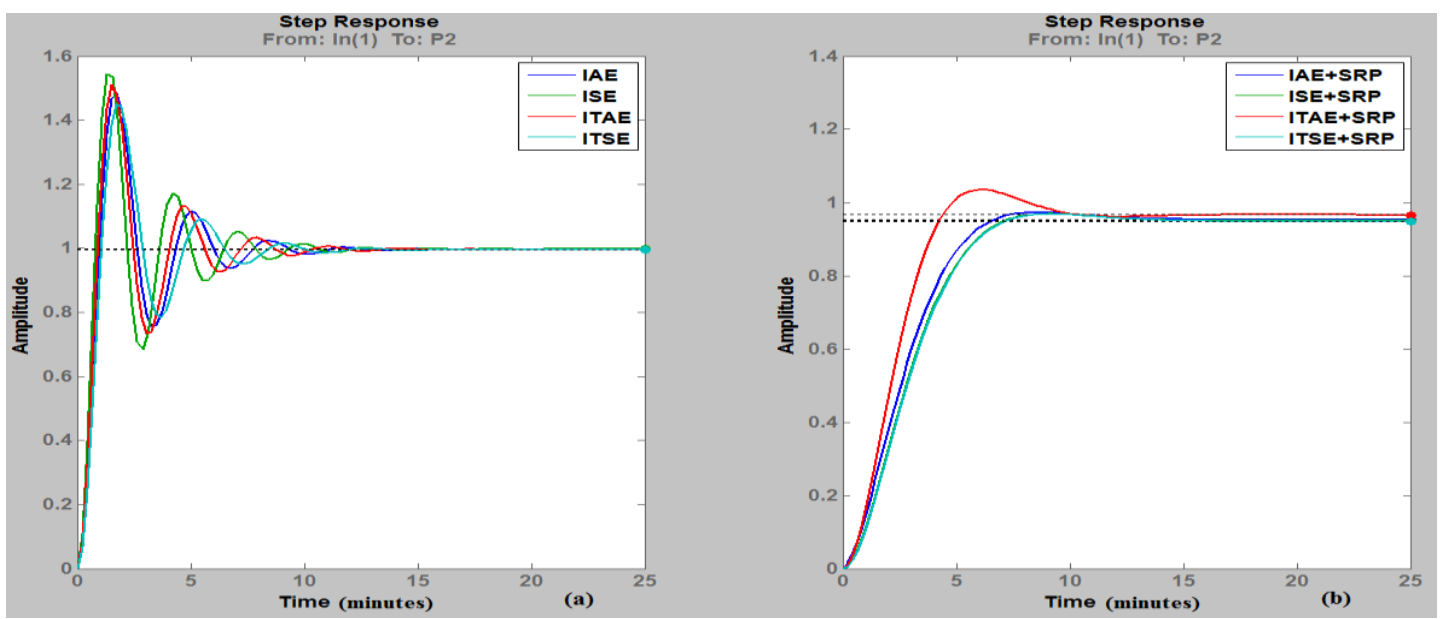

Fig. 7: Step response of $\mathrm{C}_{2}$ controllers with two groups of cost functions

Table 5 Parameters of controllers $\mathrm{C}_{1}$ using cost functions; IAE, ISE, ITAE, and ITSE, their cost functions values, step response parameters and their gain margin (GM) and phase margin (PM) (the dashed row indicates its best in SRP or Stability)

\begin{tabular}{|c|c|c|c|c|c|c|c|c|c|c|c|}
\hline $\begin{array}{c}\text { Cost } \\
\text { Function }\end{array}$ & C.F.V & Kp & $\mathbf{K i}$ & $\mathbf{N}$ & $\begin{array}{c}\text { Tr } \\
(\mathrm{min})\end{array}$ & $\begin{array}{c}\text { Ts } \\
\text { (min) }\end{array}$ & $\begin{array}{l}\text { Mp } \\
(\%)\end{array}$ & Ess & SRP & $\begin{array}{l}\text { GM } \\
\text { (dB) }\end{array}$ & $\begin{array}{c}\text { PM } \\
\text { (deg) }\end{array}$ \\
\hline IAE & 4.1725 & 689.4724 & 70.3774 & 4.1725 & 2.61 & 14.75 & 20.91 & 0 & 38.27 & 5.78 & 55.23 \\
\hline ISE & 2.9708 & 964.0934 & 94.6058 & 2.9708 & 2.27 & 21.09 & 39.41 & 1.11e-16 & 62.77 & 4.59 & 40.96 \\
\hline ITAE & 15.8595 & 572.3759 & 59.0390 & 15.8595 & 2.95 & 19.48 & 14.32 & 0 & 36.74 & 5.82 & 61.76 \\
\hline ITSE & 6.0417 & 960.3947 & 87.6701 & 6.0417 & 2.28 & 20.78 & 36.45 & $-2.22 \mathrm{e}-16$ & $\mathbf{5 9 . 5 2}$ & 4.76 & 42.75 \\
\hline
\end{tabular}

Table 6 Parameters of controllers $C_{1}$ using cost functions; IAE+SRP, ISE+SRP, ITAE+SRP, and ITSE +SRP, their cost functions values, step response parameters and their gain margin (GM) and phase margin (PM)

\begin{tabular}{|c|c|c|c|c|c|c|c|c|c|c|c|c|}
\hline $\begin{array}{c}\text { Cost } \\
\text { Function }\end{array}$ & P.I.V & C.F.V & Kp & $\mathbf{K i}$ & $\mathbf{N}$ & $\begin{array}{c}\text { Tr } \\
(\mathrm{min})\end{array}$ & $\begin{array}{c}\text { Ts } \\
\text { (min) }\end{array}$ & $\begin{array}{l}\text { Mp } \\
(\%)\end{array}$ & Ess & SRP & $\begin{array}{l}\text { GM } \\
\text { (dB) }\end{array}$ & $\begin{array}{c}\text { PM } \\
\text { (deg) }\end{array}$ \\
\hline IAE+SRP & 4.1287 & 26.39 & 567.3865 & 54.5581 & 4.1287 & 3.10 & 12.66 & 6.50 & 0 & 22.26 & 7.20 & 64.04 \\
\hline ISE+SRP & 3.5622 & 41.08 & 602.3531 & 46.5112 & 3.5622 & 3.59 & 18.90 & 15.03 & $\mathbf{0}$ & 37.52 & 7.13 & 56.41 \\
\hline ITAE+SRP & \begin{tabular}{|c|}
45.9528 \\
\end{tabular} & 76.07 & 253.6002 & 30.0120 & 45.9528 & 10.57 & 17.77 & 1.77 & $-2.22 \mathrm{e}-16$ & 30.12 & 15.11 & 70.21 \\
\hline ITSE+SRP & 5.5195 & 41.62 & 653.0849 & 83.8868 & 5.5195 & 2.92 & 13.77 & 19.41 & 0 & 36.10 & 7.78 & 51.60 \\
\hline
\end{tabular}

Table 7 Parameters of controllers $C_{2}$ using cost functions; IAE, ISE, ITAE, and ITSE, their cost functions values, step response parameters and their gain margin (GM) and phase margin (PM) (the dashed row indicates its best in SRP or Stability)

\begin{tabular}{|c|c|c|c|c|c|c|c|c|c|c|c|}
\hline $\begin{array}{c}\text { Cost } \\
\text { Function }\end{array}$ & C.F.V & $\mathbf{Z}$ & $\mathbf{p}$ & $\mathbf{k}$ & $\begin{array}{c}\operatorname{Tr} \\
(\mathrm{min})\end{array}$ & $\begin{array}{c}\text { Ts } \\
\text { (min) }\end{array}$ & $\begin{array}{l}\text { Mp } \\
(\%)\end{array}$ & Ess & SRP & $\begin{array}{l}\text { GM } \\
\text { (dB) }\end{array}$ & $\begin{array}{c}\text { PM } \\
\text { (deg) }\end{array}$ \\
\hline IAE & 1.7106 & -113.6 & -78.9 & -1660.1 & 0.65 & 8.87 & 48.95 & $42 \mathrm{e}-4$ & 58.48 & 35.93 & 24.78 \\
\hline ISE & 0.7514 & -166.8 & $\begin{array}{l}-77.7 \\
\end{array}$ & -1554.6 & 0.54 & 8.90 & 54.83 & 30 e-4 & 64.27 & 27.91 & 20.55 \\
\hline ITAE & 4.4548 & -200.0 & -117.1 & -1592.6 & 0.60 & 8.40 & 51.61 & $37 \mathrm{e}-4$ & 60.61 & 35.43 & 23.25 \\
\hline ITSE & 0.7074 & -162.8 & -151.0 & -1909.9 & 0.72 & 9.24 & 45.51 & 48 e-4 & 55.46 & 55.75 & 27.01 \\
\hline
\end{tabular}


Table 8 Parameters of controllers $\mathrm{C}_{2}$ using cost functions; IAE+SRP, ISE+SRP, ITAE+SRP, and ITSE +SRP, their cost functions values, step response parameters and their gain margin (GM) and phase margin (PM)

\begin{tabular}{|c|c|c|c|c|c|c|c|c|c|c|c|c|}
\hline $\begin{array}{c}\text { Cost } \\
\text { Function }\end{array}$ & P.I.V & C.F.V & $\mathbf{z}$ & p & $\mathbf{k}$ & $\begin{array}{c}\mathrm{Tr} \\
(\mathrm{min})\end{array}$ & $\begin{array}{c}\text { Ts } \\
\text { (min) }\end{array}$ & $\begin{array}{l}\text { Mp } \\
(\%)\end{array}$ & Ess & SRP & $\begin{array}{l}\text { GM } \\
\text { (dB) }\end{array}$ & $\begin{array}{c}\text { PM } \\
\text { (deg) }\end{array}$ \\
\hline IAE+SRP & 3.8079 & 16.118 & -6 & -40.6 & -1401.6 & 4.15 & 6.12 & 2.00 & 0.046 & 12.31 & inf & 73.08 \\
\hline ISE+SRP & 2.1784 & 15.102 & -34 & -169.3 & -936.3 & 4.35 & 6.52 & 2.00 & 0.05 & 12.92 & inf & 72.57 \\
\hline ITAE+SRP & 12.318 & $\mathbf{3 1 . 3 3 8}$ & -29.8 & -153.3 & -1469.3 & 2.93 & 8.91 & 7.15 & $\begin{array}{l}0.034 \\
\end{array}$ & 19.02 & inf & 64.22 \\
\hline ITSE+SRP & 4.0305 & 17.029 & \begin{tabular}{|l|}
-77.4 \\
\end{tabular} & -189.6 & -457.3 & 4.38 & 6.57 & 2.00 & 0.051 & 13.00 & inf & 72.50 \\
\hline
\end{tabular}

\section{ANALYSIS OF RESULTS}

From previous results it could be concluded that:-

- Generally, the second proposed group of cost functions; such as (IAE+SRP, ISE+SRP, ITAE+SRP, and ITSE+SRP) for tuning level controller and decoupler controller for the evaporator system give best performance and stability than the first group of cost functions; such as (IAE, ISE, ITAE, and ITSE)

-Also ITAE cost function gives best performance in the first group of cost functions for tuning PI level controller and PI concentration controller $\left(\mathrm{C}_{1}\right)$ for the evaporator system and sometimes also gives best stability as in controller $\mathrm{C}_{1}$ as shown in Tables 3 and 5.

- ITSE cost function gives best performance and stability in the first group of cost functions for tuning lead operating pressure controller $\left(\mathrm{C}_{2}\right)$ of the decoupler controller for the evaporator system as shown in Table7.

- (ISE+SRP) cost function gives best performance and stability in the second proposed group of cost functions for tuning level controller as indicated in Table 4.

- (IAE+SRP) cost function gives best performance in the second proposed group of cost functions for tuning controllers $\mathrm{C}_{1}$ and $\mathrm{C}_{2}$. Also it gives the best stability for tuning $\mathrm{C}_{2}$ as shown in Figures [6(b) and 7(b)] and Tables (8 and 10).

From Figures ( $8 \mathrm{a}, 8 \mathrm{~b}, 9 \mathrm{a}$ and $9 \mathrm{~b}$ ), it could conclude that:-

-The proposed decoupler controllers for the evaporator system using GA depending on two groups of cost functions achieved ideal decoupler between control loops since $\mathrm{d}_{1}(\mathrm{~s})$ and $\mathrm{d}_{2}(\mathrm{~s})$ cancel the effect of the coupling between the control loops (P100-X2) and (F200-P2), respectively; especially, the decoupler $\mathrm{d}_{1}$ eliminates the great effect of the input Product Composition set point (X2sp) on the output Operating Pressure (P2).

Figures (10a, 10b, 11a, 11b, 12a and 12b) show the degree of the robustness of the proposed evaporator control systems using GA depending on two group of cost functions with respect to some variations of the disturbance feed flow rate F1 (30\% increase and $30 \%$ decrease) and some variations of the disturbance feed composition X1(100\% increase and 100\% decrease).

\section{CONCLUSION}

In this paper a Genetic algorithm (GA) algorithm was presented as an intelligent procedure for designing of optimal evaporator control system. Simulation results demonstrate that our proposed method using cost functions ISE plus summation of step response parameters such; rise time $\mathrm{Tr}$, settling time $\mathrm{Ts}$, maximum overshoot $\mathrm{Mp}$ and steady state error Ess. (ISE + SRP) and (IAE+SRP) cost functions are more efficient and robust compared with the ordinary tuning methods using performance indices only.

\section{ACKNOWLEDGMENTS}

Our thanks to the colleagues of Hot Laboratory and Waste Management Center, Atomic Energy Authority ,especially Prof. Dr. A. M. El-kamash, who have contributed towards the development of this work. 

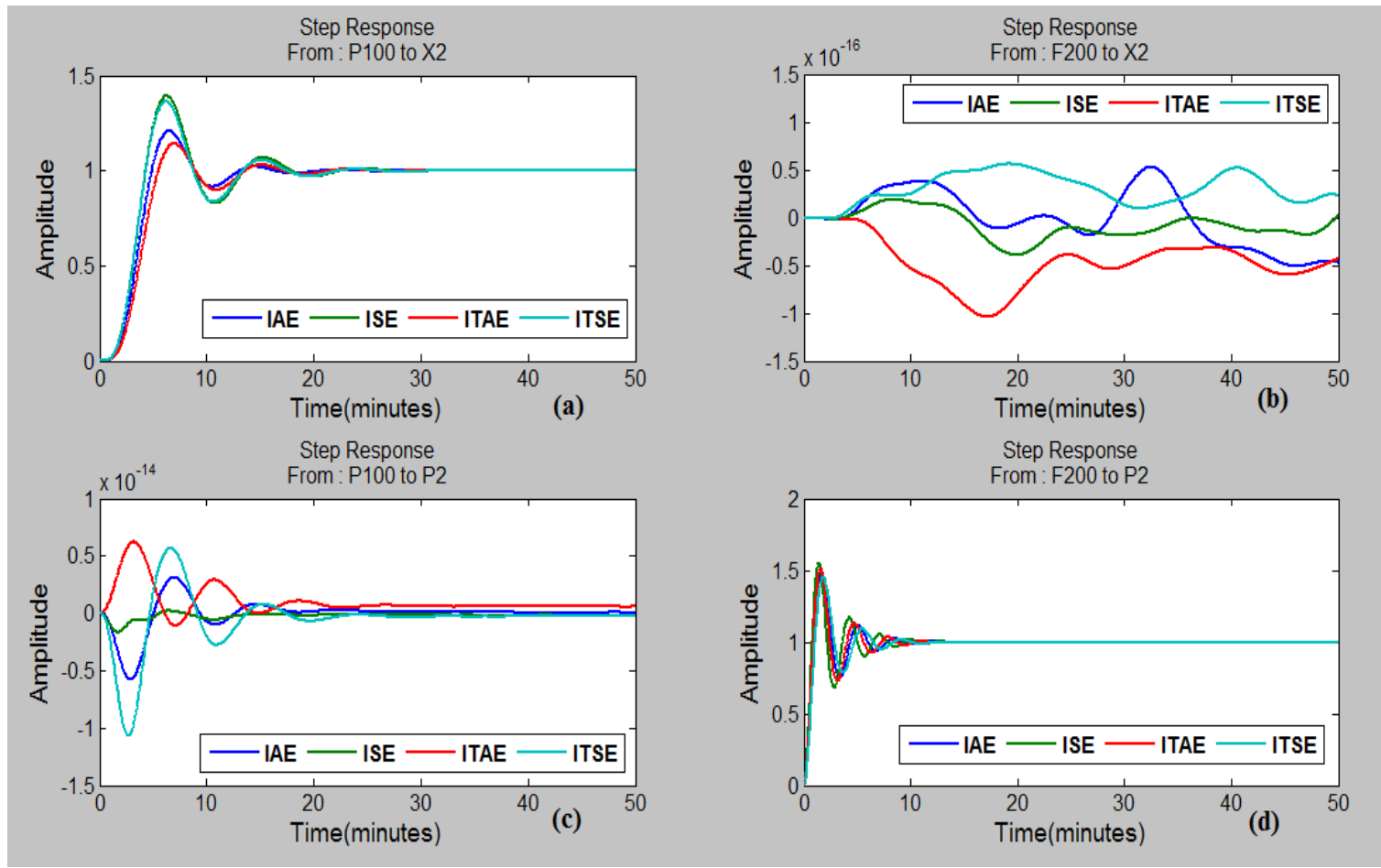

Fig 8a: Step responses of proposed decoupler controllers using first group of cost functions (IAE, ISE, ITAE, and ITSE)
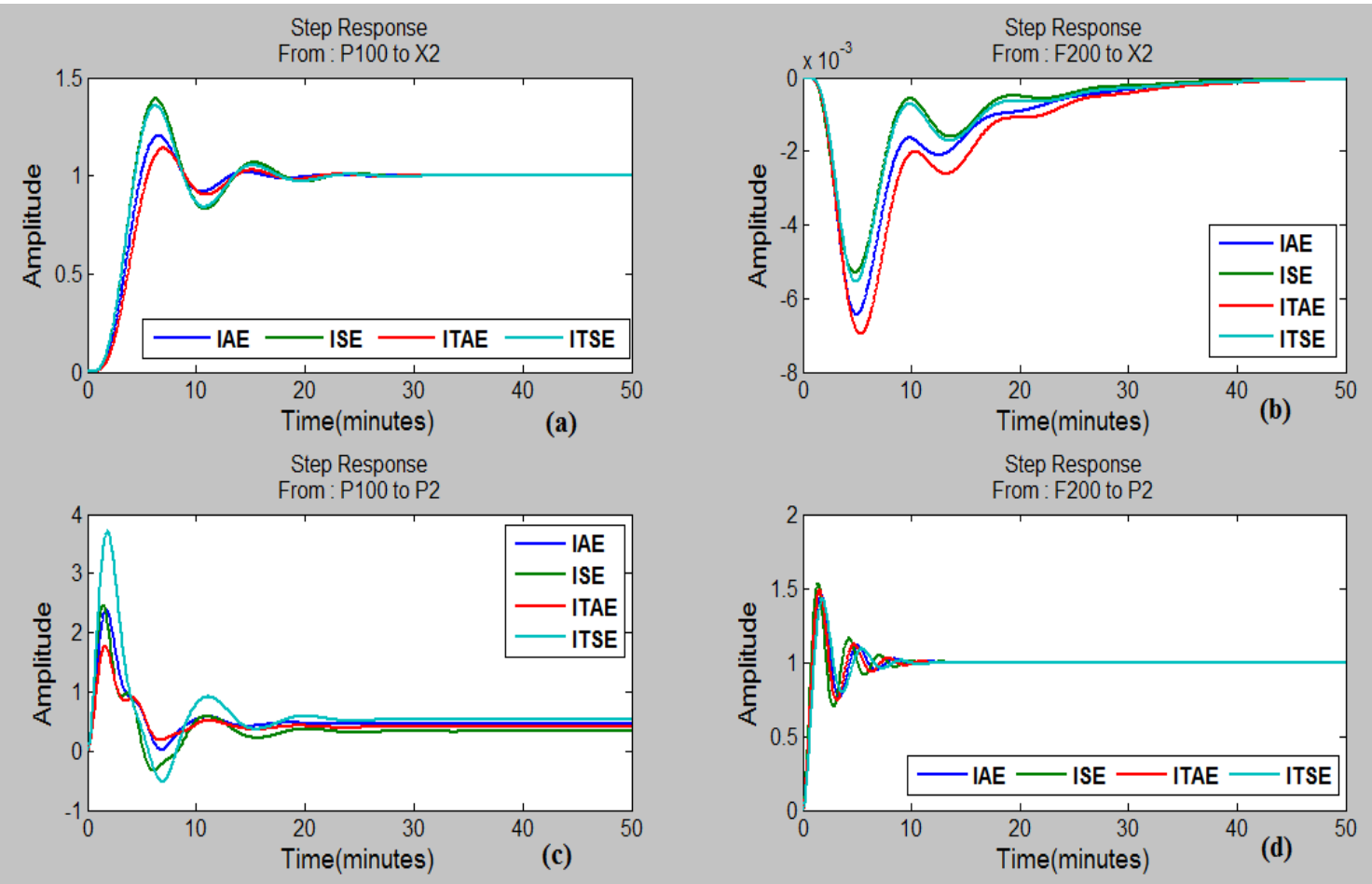

Fig 8b: Step responses of proposed evaporator control systems without decouplers $\left(d_{1}\right.$ and $\left.d_{2}\right)$ using first group of cost functions (IAE, ISE, ITAE, and ITSE) 

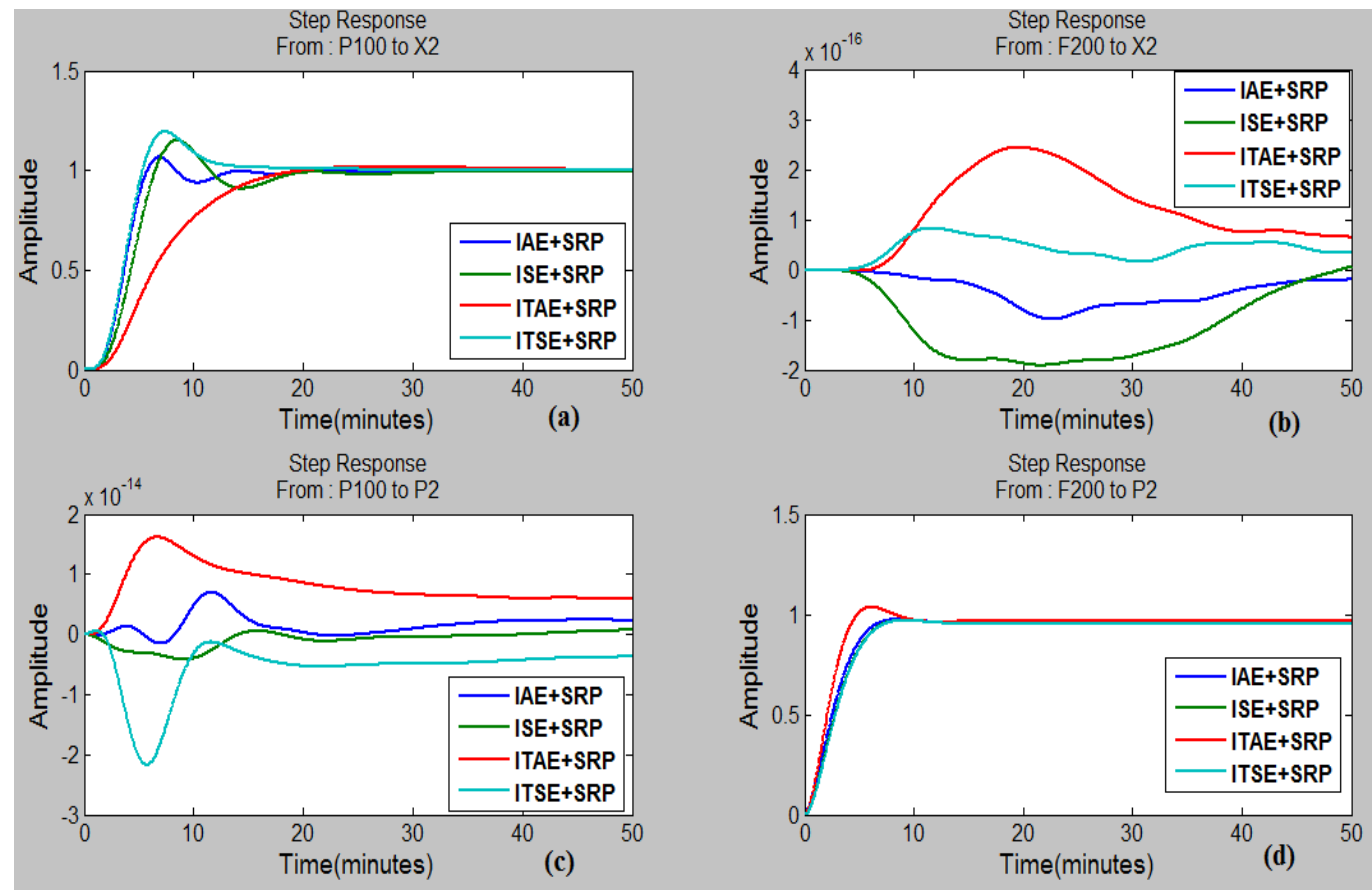

Fig 9a: Step responses of proposed decoupler controllers using with second group of cost functions (IAE+SRP, ISE+SRP, ITAE+SRP, and ITSE+SRP)
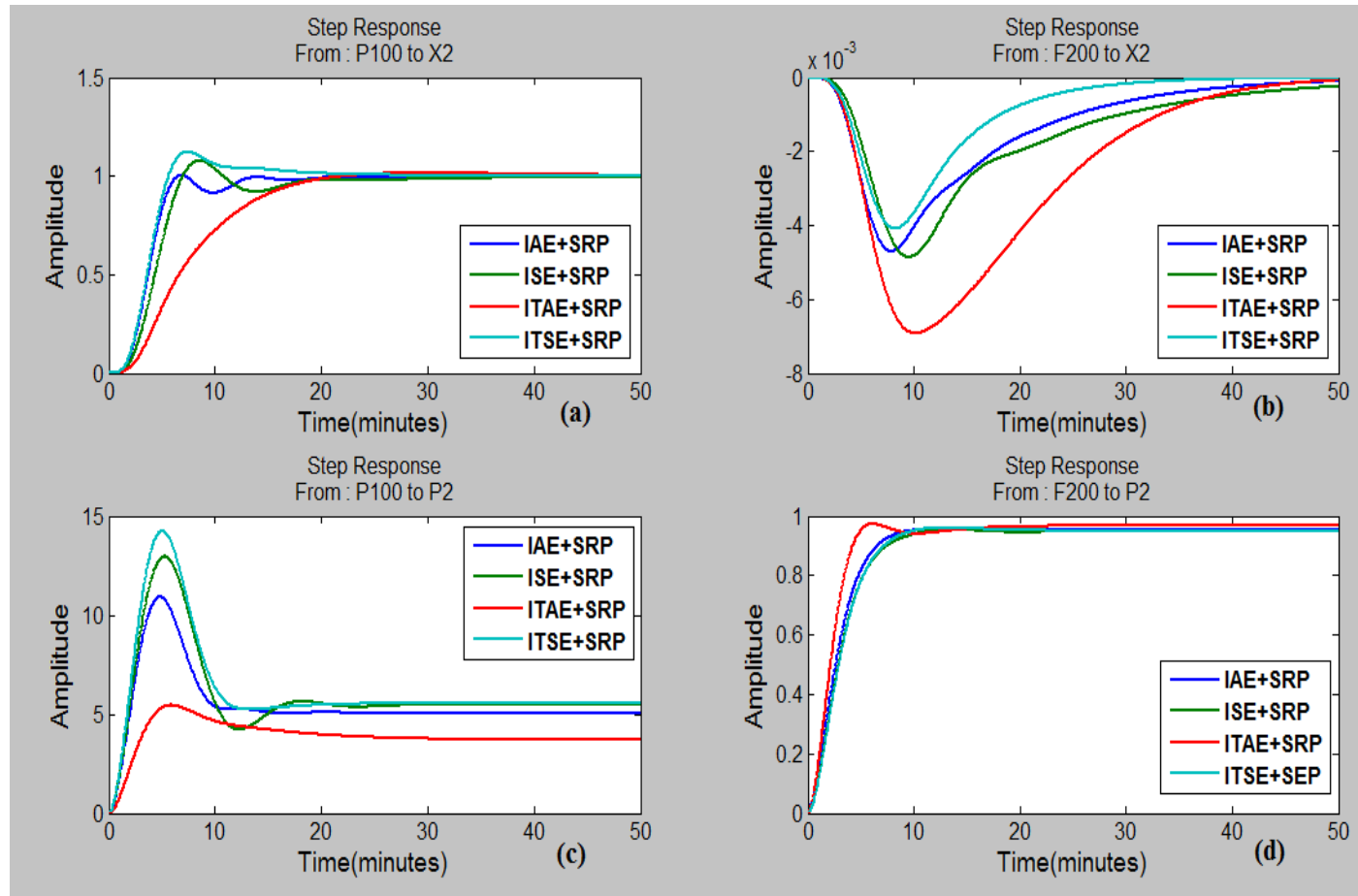

Fig 9b: Step responses of proposed evaporator control systems without decouplers $\left(d_{1}\right.$ and $\left.d_{2}\right)$ using second group of cost functions ((IAE+SRP, ISE+SRP, ITAE+SRP, and ITSE+SRP) 

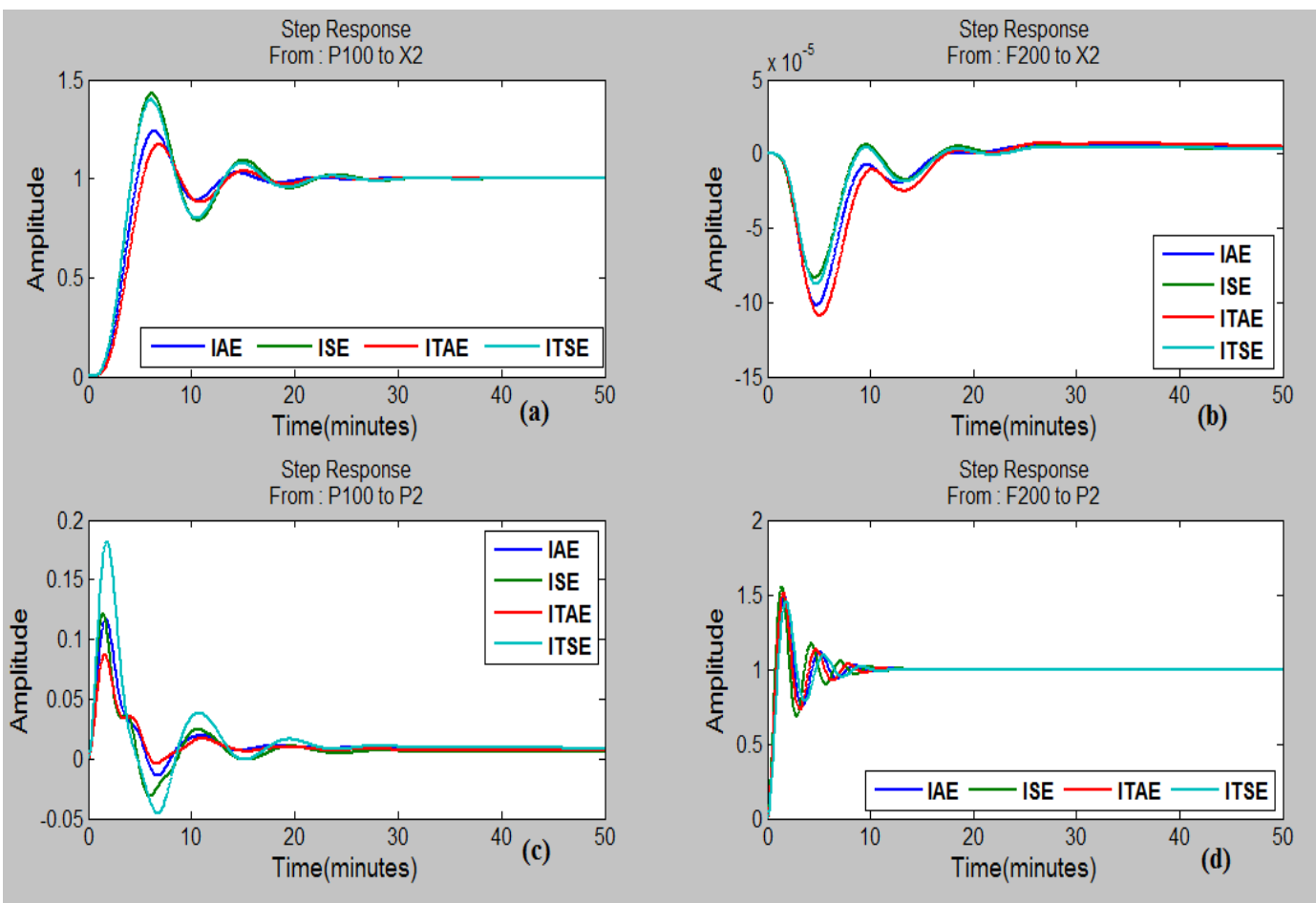

Fig 10a: Response of the proposed evaporator control systems using first group of cost functions (IAE, ISE, ITAE, and ITSE) to step change in disturbance variable $\mathrm{F} 1$ of $30 \%$ increase

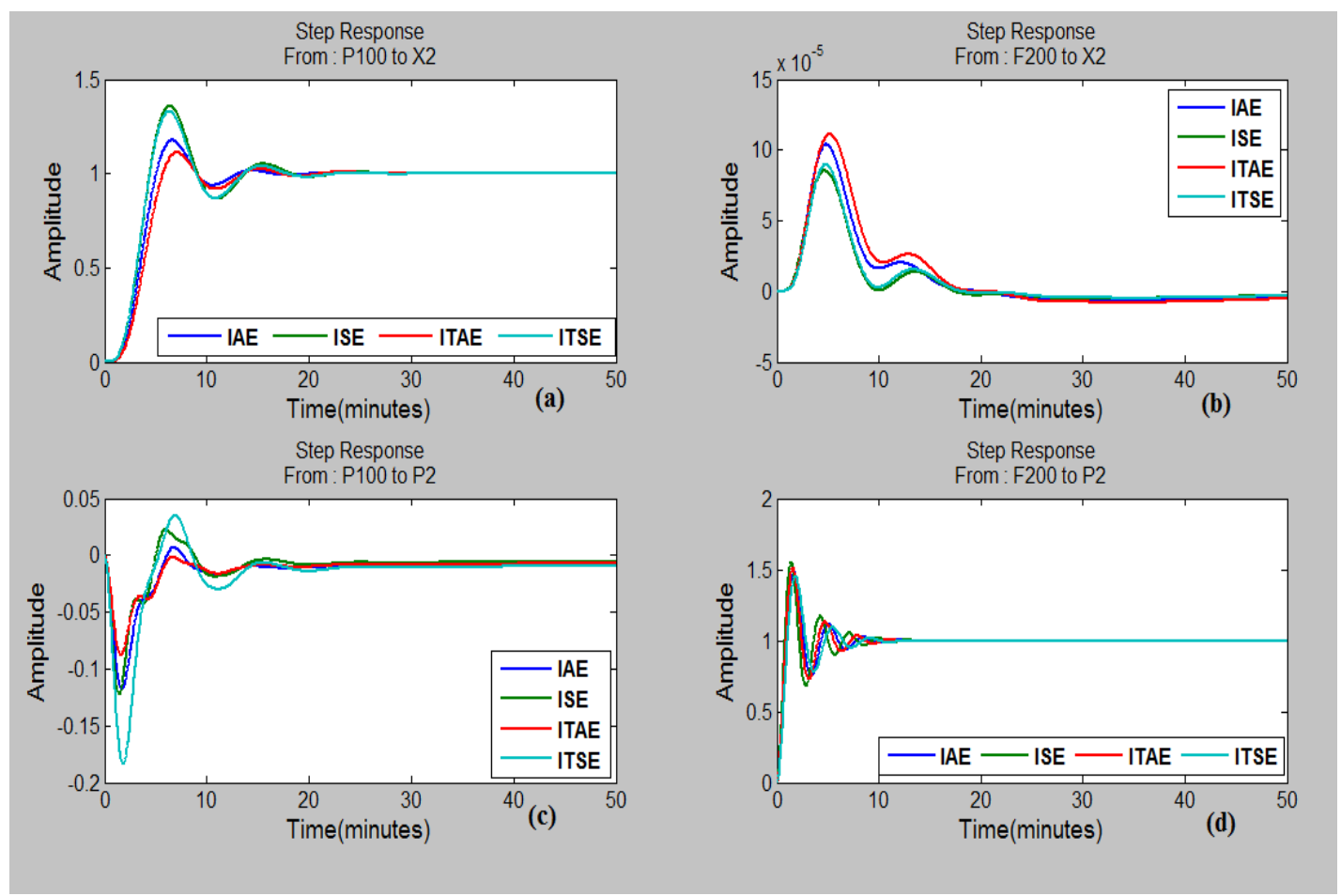

Fig 10b: Response of the proposed evaporator control systems using first group of cost functions (IAE, ISE, ITAE, and ITSE) to step change in disturbance variable $\mathrm{F} 1$ of $30 \%$ decrease 


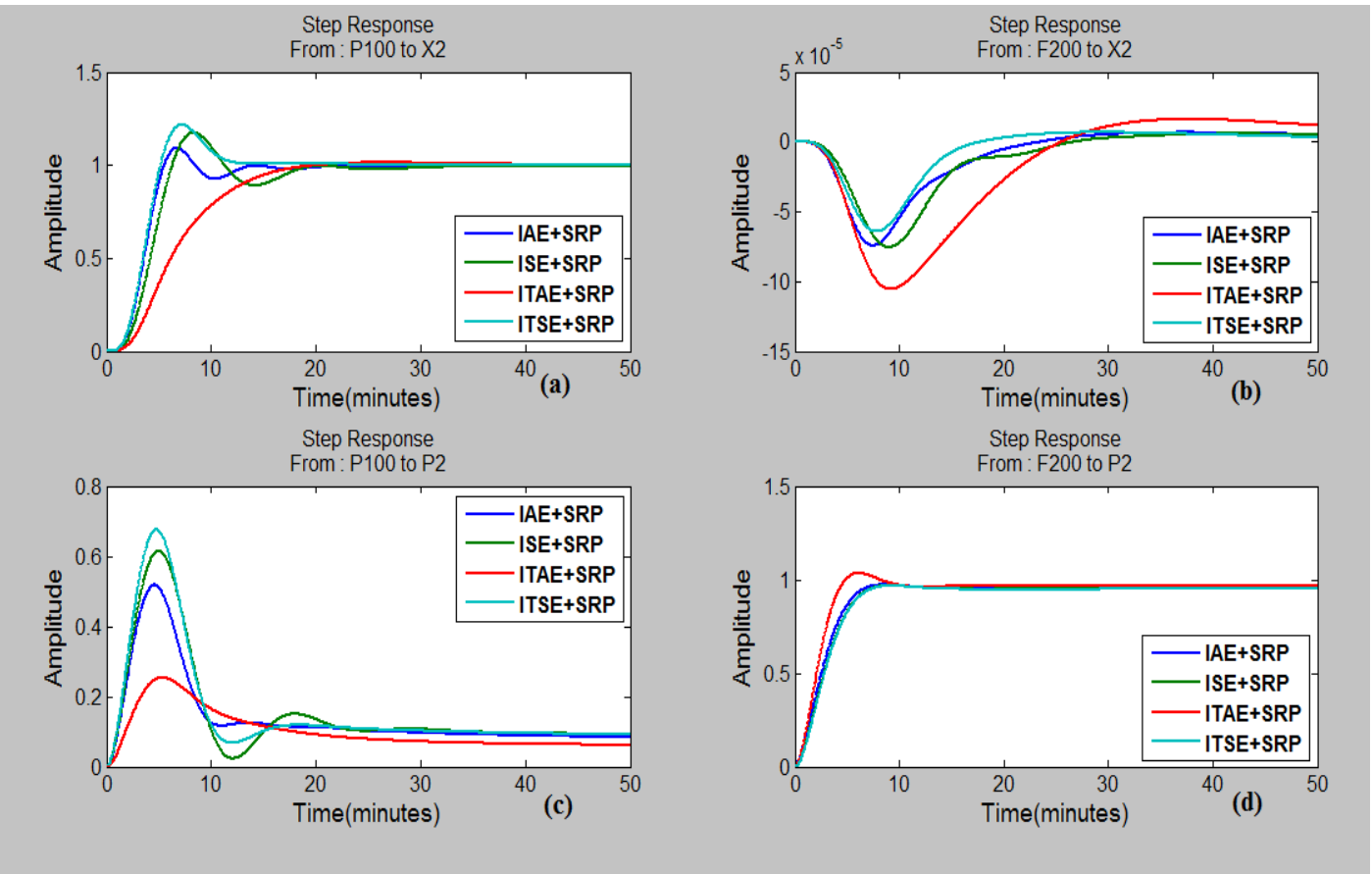

Fig 11a: Response of the proposed evaporator control systems using second group of cost functions ((IAE+SRP, ISE+SRP, ITAE+SRP, and ITSE+SRP) to step change in disturbance variable F1 of $30 \%$ increase
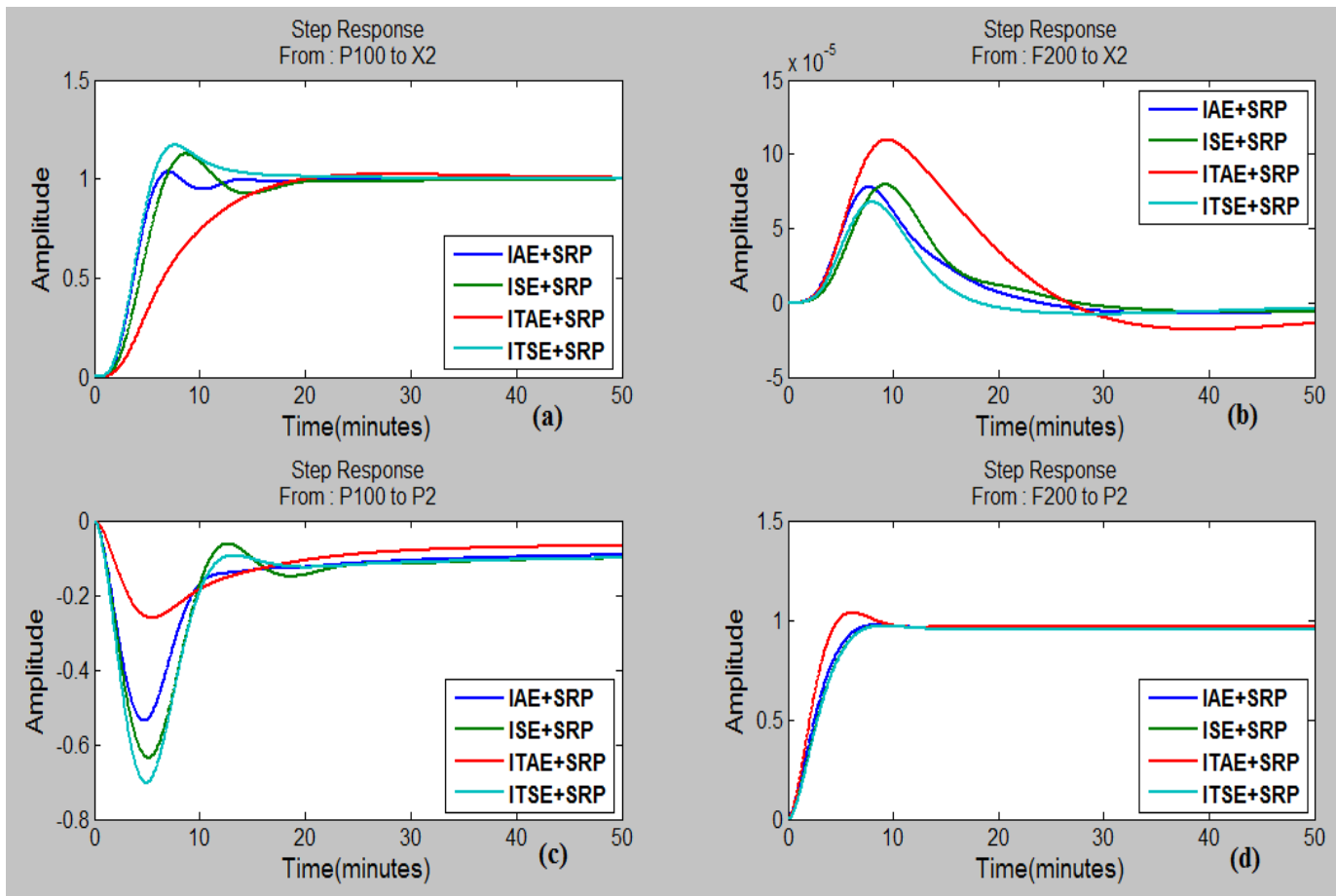

Fig 11b: Response of the proposed evaporator control systems using second group of cost functions ((IAE+SRP, ISE+SRP, ITAE+SRP, and ITSE+SRP) to step change in disturbance variable F1 of $30 \%$ decrease 

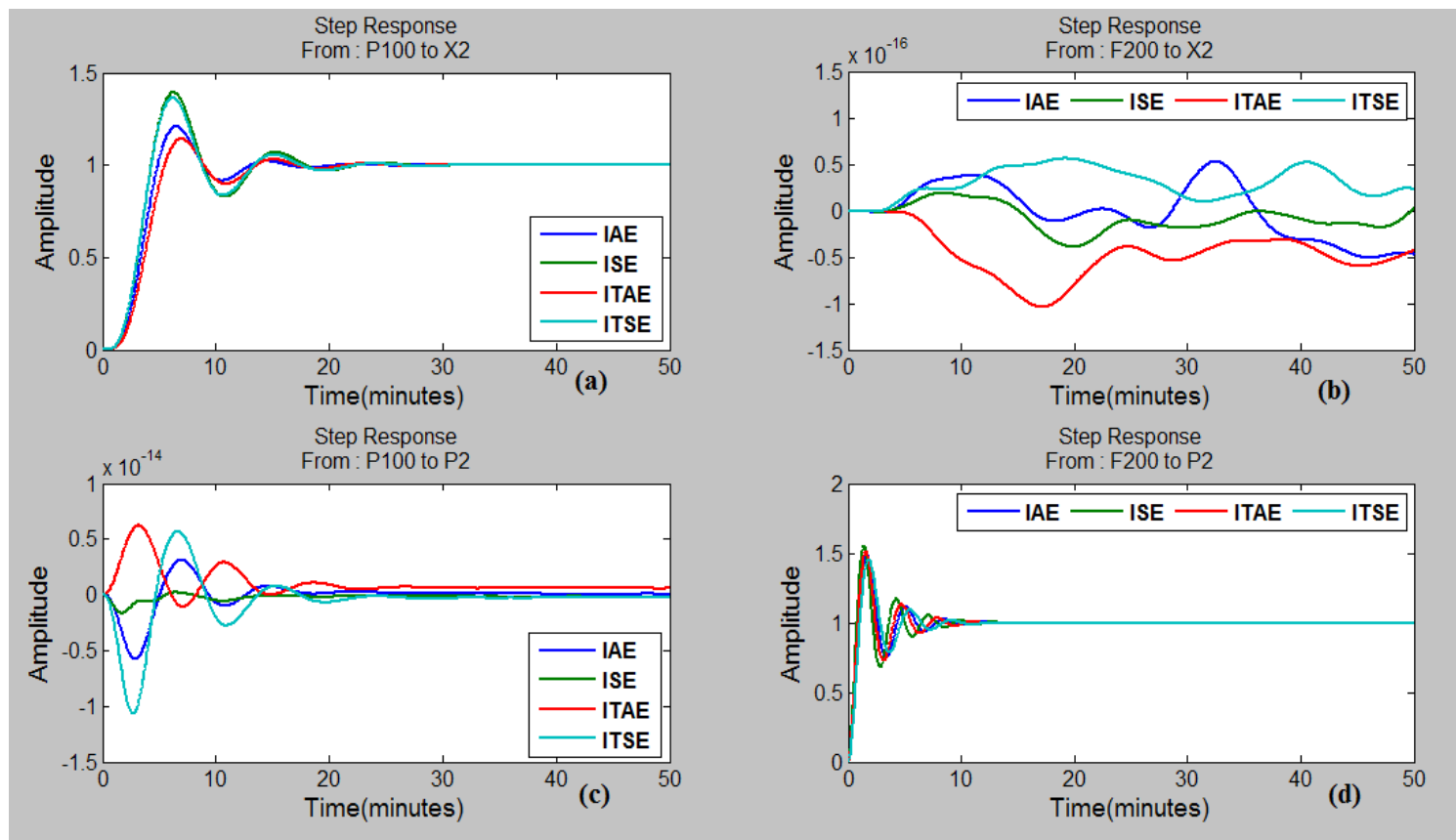

Fig 12a: Response of the proposed evaporator control systems using first group of cost functions ((IAE, ISE, ITAE, and ITSE) to step change in disturbance variable $\mathrm{X} 1$ of $100 \%$ increase or $100 \%$ decrease
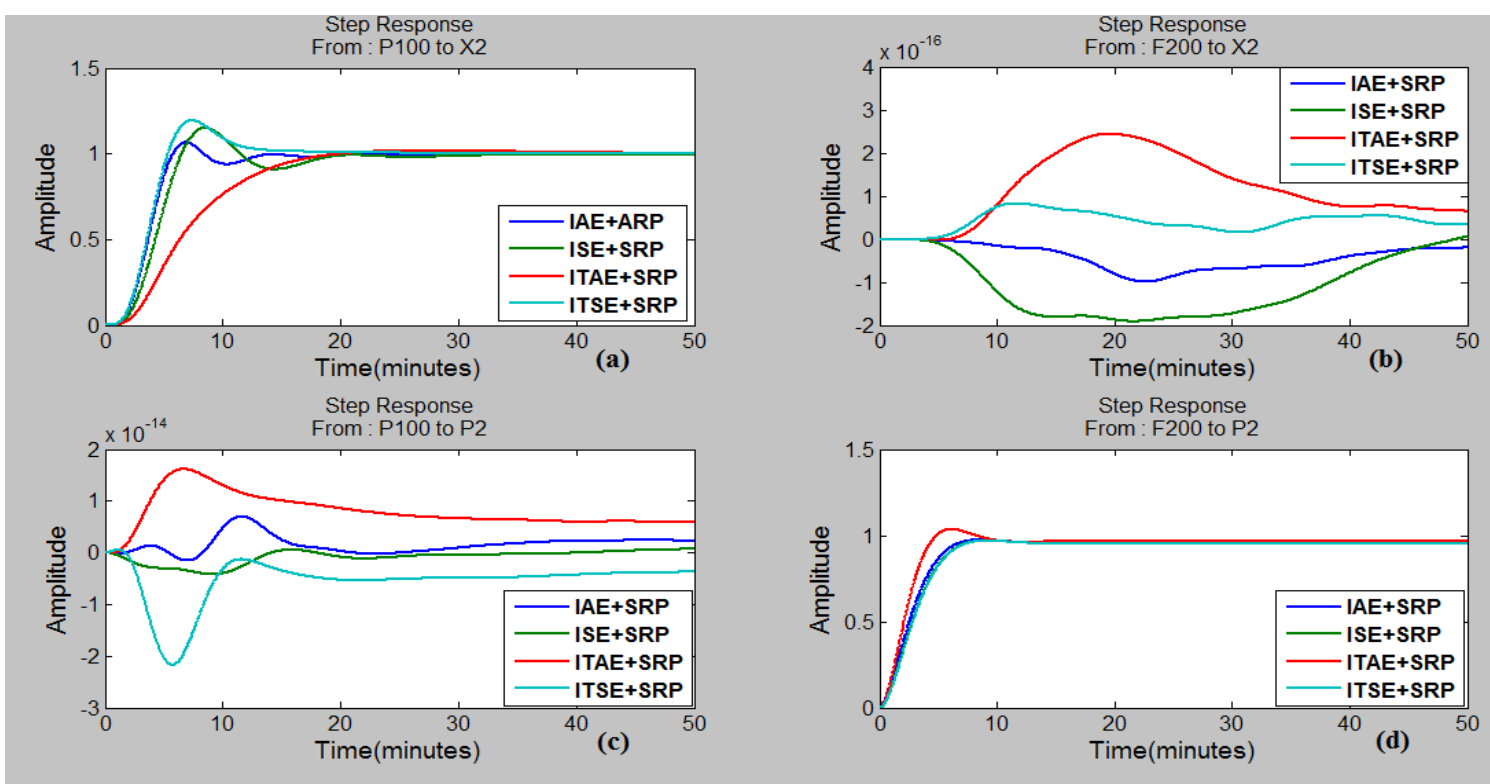

Fig 12b: Response of the proposed evaporator control systems using second group of cost functions ((IAE+SRP, ISE+SRP, ITAE+SRP, and ITSE+SRP) to step change in disturbance variable X1 of $100 \%$ increase or $100 \%$ decrease

Appendix A:

Table 1a. Steady-State of the Evaporator Plant for the Inputs

\begin{tabular}{|c|c|c|c|c|c|c|c|}
\hline F2 & P100 & F200 & F3 & F1 & X1 & T1 & T200 \\
{$[\mathrm{Kg} / \mathrm{min}]$} & {$[\mathrm{Kpa}]$} & {$[\mathrm{Kg} / \mathrm{min}]$} & {$[\mathrm{Kg} / \mathrm{min}]$} & {$[\mathrm{Kg} / \mathrm{min}]$} & {$[\%$ of mass $]$} & {$\left[{ }^{\circ} \mathrm{C}\right]$} & {$\left[{ }^{\circ} \mathrm{C}\right]$} \\
\hline 2.0 & 194.7 & 208.0 & $\mathbf{5 0 . 0}$ & $\mathbf{1 0 . 0}$ & $\mathbf{5 . 0}$ & $\mathbf{4 0 . 0}$ & $\mathbf{2 5 . 0}$ \\
\hline
\end{tabular}


Table 2a. Steady-State of the Evaporator Plant for the Outputs.

\begin{tabular}{|c|c|c|}
\hline L2[m] & X2 [\%of mass] & P2[Kpa] \\
\hline 1.0 & 25.0 & 50.5 \\
\hline
\end{tabular}

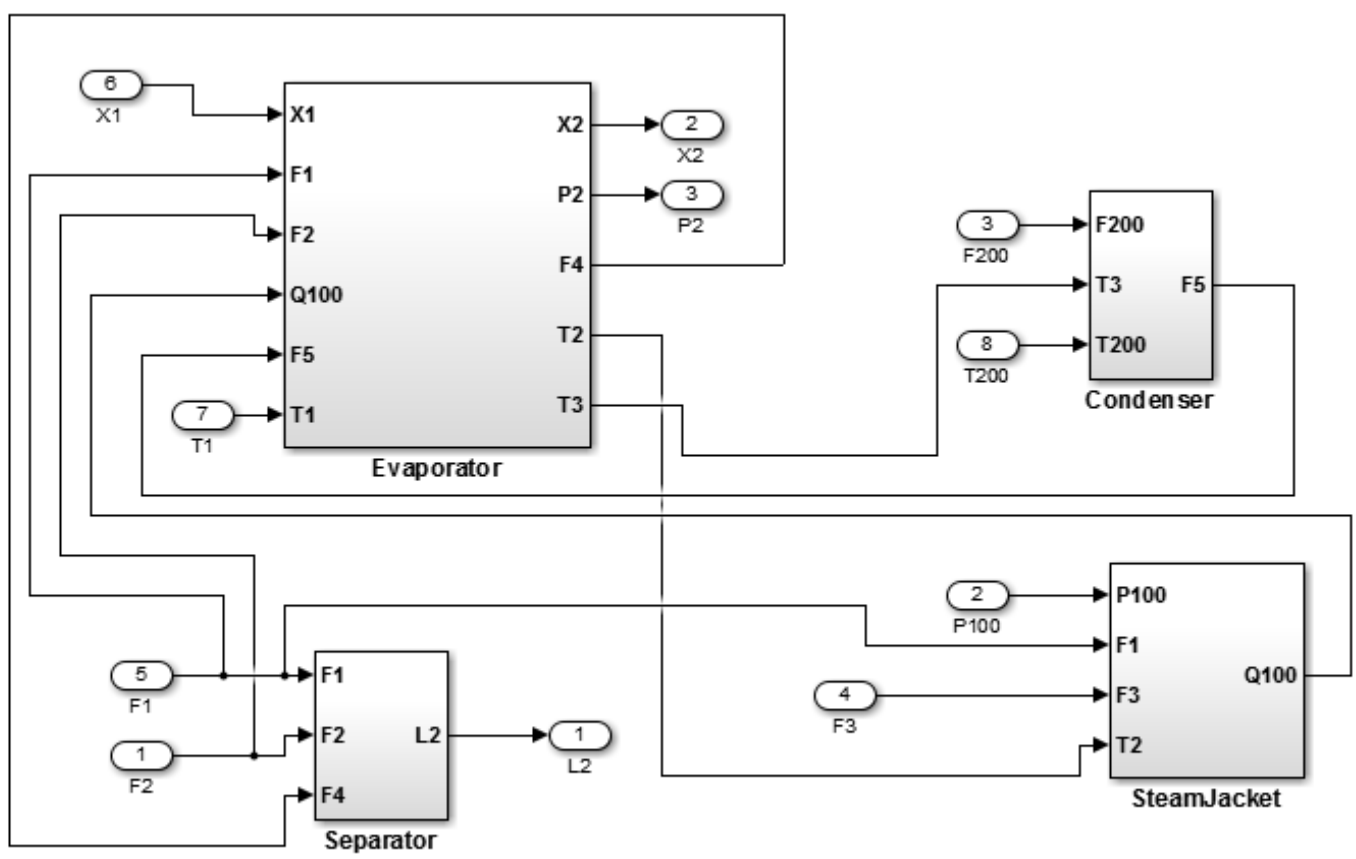

Fig 1a: A simulink model of the forced circulation evaporator consists of subsystems $\left({ }^{1}\right.$ separator, ${ }^{2}$ evaporator, ${ }^{3}$ condenser, ${ }^{4}$ steam jacket)

\section{REFERENCES}

[1] Bansal, H.O., Sharma, R., and Shreeraman, P. 2012. PID controller tuning techniques: a review. J Control Eng Technol.; 2 (4):168-176.

[2] Panda, S. 2011. Differential evolution algorithm for SSSC-based damping controller design considering time delay. J Franklin Inst., 348(8):1903-1926.

[3] Mohamed, A.W., Sabry, H.Z., and Khorshid M. 2012. An alternative differential evolution algorithm for global optimization. J Adv Res.,3(2):149-165.

[4] Maldonado, L. B., Arias, H. P., Romero , F. A., and Granda, J.C., " Intelligent systems applied to the control of a distilling binary column", 2016 IEEE International Conference on Automatica (ICAACCA),2016,Pages: 1 - 9, IEEE Conference Publications

[5] Poongodi, P., Madhusudhanan, R. and Prema, N., " Implementation of Temperature Process Control using Soft Computing Techniques", proceedings of the World Congress on Engineering 2016, Vol I WCE 2016, June 29 - July 1, 2016, London, U.K.

[6] Pamela, D., and Jebarajan, T., "Intelligent Controller for Temperature Process", International Journal of Control and Automation, 2013, Vol.6, No.5, pp.191-198 http://dx.doi.org/10.14257/ijca.2013.6.5.18
[7] Lakshmi Narayana, K. V., Kumar, V. N., Dhivya,M. and Prejila Raj, R., "Application of Ant Colony Optimization in Tuning a PID Controller to a Conical Tank", Indian Journal of Science and Technology, January 2015, Vol 8(S2), 217-223,

[8] Jagatheesan, K., Anand, B., and Omar, M., "Design of Proportional - Integral - Derivative controller using Ant Colony Optimization technique in multi-area Automatic Generation Control", International Journal on Electrical Engineering and Informatics, December 2015, Vol. 7, No. 4.

[9] Jagatheesan, K. , Anand, B. , Dey, N. , Gaber, T., Hassanien, A. , Kim, T. , " A Design of PI Controller using Stochastic Particle Swarm Optimization in Load Frequency Control of Thermal Power Systems", 2015 Fourth International Conference on Information Science and Industrial Applications (ISI), 2015,p.p 25-32, IEEE Conference Publications

[10] Miavagh, F M. , Miavaghi, E. A. A. , Ghiasi, A. R. Asadollahi, M. , "Applying of PID, FPID, TID and ITID controllers onAVR system using particle swarm opt imization (PSO)",2015 2nd International Conference on Knowledge-Based Engineering and Innovation (KBEI), IEEE Conference Publications

[11] Noshahri, H.,and Kharrati, H., "PID controller design for unmanned aerial vehicle using genetic algorithm", 2014 
IEEE 23rd International Symposium on Industrial Electronics (ISIE), 2014, p.p 213-217, IEEE Conference Publications

[12] Mohammed, N. F., Xiuzhen, M., and Enzhe, S., "Tuning of PID controller for diesel engines using geneti c algorithm", 2013 IEEE International Conference on Mechatronics and Automation, 2013, p.p $1523-1527$, IEEE Conference Publications

[13] Mohammed, N. F., Xiuzhen, M., and Enzhe, S.; Xiuzhen, M.; Hayat, Q., "Tuning of PID controller of synchronous generators using genetic algorithm”, 2014 IEEE International Conference on Mechatronics and Automation, (2014) 1544-1548, IEEE Conference Publications

[14] Patil, U., Katkol, P., and Havagondi, M., Patil, A., "Genetic algorithm approach for controlling nonlinear sy stems", 2014 International Conference on Circuits, Power and ComputingTechnologies (ICCPCT)-2014],p.p 944 -949, IEEE Conference Publications

[15] Ogata. K, 2009. Modern Control Engineering. $5^{\text {th }}$ edition, Prentice-Hall International.

[16] Krohling, R.A., Rey, J.P. 2001. Design of optimal disturbance rejection PID controllers using genetic algorithms. IEEE Trans Evol Comput. ; 5(1):78-82.

[17] Yegiireddy, N. K., and Panda, S., "Design and Performance analysis of PID controller for an AVR system using multi-objective non-dominated shorting genetic algorithm-II", 2014 International Conference on Smart Electric Grid (ISEG), 2014, p.p 1-7, IEEE Conference Publications

[18] Marzaki, M. H. , Tajjuddin, M., Rahiman, M. H. F., and Adnan, R., "Performance of FOPI with Error filter Based on Controllers Performance Criterion (ISE, IAE and ITAE) ", $201510^{\text {th }}$ Asian Control Conference (ASCC), 2015, p.p 1-5, IEEE Conference Publications

[19] Chandrasekar, P., and Ponnusamy, L., "Passivity based level controller design applied to a nonlinear SISO system", 2013 International Conference on Green Computing, Communication and Conservation of Energy(ICGCE), 2013, p.p 392-396, IEEE Conference Publications

[20] Pan, F., Liao, H., Luo, J., and Xue, Y., "ITAE-Optimal PI Controller Based on Genetic Algorithm for Low-order
Process with Large Time Delays", $201420^{\text {th }}$ International Conference on Automation and Computing, 2014, p.p 143-139, IEEE Conference Publications

[21] Maiti, D., Acharya, A., Chakraborty, M., Konar, A.and Janarthanan, R., "Tuning PID and PI $\lambda \mathrm{D} \delta$ Controllers using the Integral Time Absolute Error Criterion",2008 4th International Conference on Information and Automation for Sustainability, 2008,p.p 457-462, IEEE Conference Publications

[22] Pitteea, A. V., Ah King, R. T. F., and Rughooputh, H. C. S., "Intelligent Controller for Multiple-Effect Evaporator in the Sugar Industry", 2004 IEEE International Conference on Industrial Technology (ICIT '04), 2004, Vol. 3, p.p 117-182, , IEEE Conference Publication

[23] Yang, Q., Fu, S., Xue, Y., Ruan, S., and Chen, J., "Individual Intelligence Based Optimization and ITS Application to ITAE Standards Forms", 2014 10th International Conference Computational Inelligence and Security, 2014, p.p 109-113, IEEE Conference Publication

[24] Nagrath, I.J., and Gopal, M., 2007. Control Systems Engineering. Fifth Edition, ISBN: 81-224-2008-7, New Age International Publishers.

[25] Krohling, R.A., Rey, J.P., 2001. Design of optimal disturbance rejection PID controllers using genetic algorithms. IEEE Trans Evol Comput., 5(1):78-82.

[26] Newell, R. B. and Lee, P. L., 1989.Applied Process Control: A case study. Prentice-Hall of Australia Ltd.

[27] MatlabR2.14a (8.3.0.532), 32bit (win32), Febrauary 11, 2014.

[28] Haupt, R. L., and Haupt, S. E., 2004. Practical Genetic Algorithms. 2nd Edition, John Wiley \&Sons,Inc.

[29] Mirzal, A., Yoshii, S., and Furukawa, M., "PID Parameters Optimization by Using Genetic Algorithm", STECS Journal, 2006, Vol. 8, pp. 34-43.

[30] Stefani, R. T., Shahian B., and Savant, C. J., 2002. Design of Feedback Control Systems. $4^{\text {th }}$ edition, New York, Oxford, Oxford University Press.

[31] Béla G. Lipták, 2013. Process Control: Instrument Engineers' Handbook. ButterworthHeinemann, Technology \& Engineering 